3. Phan Quan Chí Hiếu, Hà Thị Hồng Linh (2005). Hiêu quả phuc hồi vận động của phương pháp thể châm cải tiến trên bệnh nhân tai biến mach máu não. Luận án tốt nghiệp cao học Y học cố truyền, Đai hoc Ỳ dước TP. HCM̀, tr 79.

4. Ma Thị Kim Liền (2006). Nghiên cứu một số yếu tố liên quan đến mức độ đối lập trong sinh hoạt và nhu câuu phục hồi chức năng của người bệnh sau tai biến mạch máu não tại cộng đồng. Luận văn thạc sỹ, tr.25 - 37.
5. Nguyễn Thị Kim Liên (2011). Nghiên cứu phục hồi chức năng bàn tay trên bênh nhân liêt nửa người do tai biến mạch máu não. Luận văn tiến sỹ Y họ, Trường Đại học Y Hà Nội, tr. 90 - 95.

6. Nguyễn Xuân Thản (2004). Bệnh mạch máu não và tủy sống. Nhà xuất bản Y học, tr 265 - 266.

7. Vũ Thi Kim Thanh (2012). Đánh giá hiêu quả phục hồi chức năng vận động chi trên ở bệnh nhân tai biến nhồi máu vùng trền lều. Luận văn thạc sỹ y học, Đại học Y Hà Nội, tr 55.

\title{
DÂY RỐN QUẤN CỔ LÚC SINH VÀ KẾT CỤC TRÊN THAI NHI TẠI BỆNH VIỆN SẢN NHI AN GIANG
}

\section{TÓM TẮT}

Đặt vấn đê: Dây rốn quấn cổ (DRQC) là một hiện tượng thường găp vào những tháng cuối của thai kỳ và có thể gây bất lợi cho thai nhi. Mục tiêu của nghiên cứu này nhằm xác định mối liên quan giữa DRQC một vòng với kết cục bất lợi trên thai nhi. Đối tượng và phương pháp: Một nghiên cứu bệnh-chứng với tỉ lệ 1:2 thực hiện tại Phòng sinh bệnh viện Sản Nhi An Giang từ 3/2019-12/2019, nhóm bênh gồm 90 sản phụ có DRQC một vòng và nhóm chứng gôm 180 sản phụ không có DRQC. Kết quả:. DRQC một vòng khổng làm tăng nguy cơ ối nhuộm phân su, biểu đồ tim thai bất thường, sử dụng oxytocin để tăng co trong quá trình chuyển dạ, cũng như không làm tăng nguy cơ sinh mổ và trẻ ngạt sau sinh. Kết luận: Không có mối liên quan giữa DRQC một vòng với các yếu tố nguy cơ trong chuyển da và kết cục trên thai nhi.

Tư khóa: Dây rốn quấn cổ, kết cục thai nhi

\section{SUMMARY}

NUCHAL CORD AT DELIVERY AND

PERINATAL OUTCOMES AT THE WOMEN

\section{AND CHILDREN HOSPITAL OF AN GIANG}

Background: Nuchal cord is a common phenomenon in the late months of pregnancy and can be detrimental to the fetus. The objective of this study was to determine the association of nuchal cord with the unfavorable outcomes for newborns. Subjects and methods: A 1: 2 case-control study conducted at the delivery rooms at the Women and Children hospital of An Giang from 3/2019 to 12/2019, a group of 90 women with nuchal cord and a control group of 180 women without nuchal cord. Results: Nuchal cord did not increase the risk of meconium-stained amniotic fluid, abnormal cardiotocography, increased using oxytocin during labor, and did not increase

${ }^{1}$ Dại học Y Dược Cần Tho

${ }^{2}$ Bệnh viện Sản Nhi An Giang

Chịu trách nhiệm chính: Nguyễn Ngọc Rạng

Email: nguyenngocrang@gmail.com

Ngày nhận bài: 19.11.2020

Ngày phản biện khoa học: 23.12.2020

Ngày duyệt bài: 6.01.2021

\section{Nguyễn Ngọc Rạng ${ }^{1}$, Trương Kim Thuyên ${ }^{2}$}

cesarean section and postpartum asphyxia. Conclusions: There is no association between nuchal cord and risk factors for unfavoable perinatal outcomes.

Keywords: Nucal cord, perinatal outcomes

\section{I. ĐĂT VẤN ĐỀ}

Dây rốn quấn cổ (DRQC) là hiện tượng dây rốn quấn quanh cổ thai nhi một vòng hoặc nhiều vòng, thường gặp trong những tháng cuối của thai kỳ. DRQC là một trong những biến chứng thường gặp trong thai kỳ nó gây một số bất lợi cho thai nhi: nhịp tim thai giảm bất định, ối nhuộm phân su, tăng tỉ lệ mổ sanh, và chỉ số Apgar thấp, thai chết lưu [1]. Một phân tích tổng hợp gồm 145 nghiên cứu, DRQC một vòng chiếm $22 \%$ tổng số sinh và khoảng $4 \%$ trường hợp đối với trường DRQC từ hai vòng trở lên và tăng dân trong suốt thai kỳ.[2] Sự hiện diện của số vòng DRQC phụ thuộc vào lượng nước ối và sự cử động của thai nhi. DRQC thường xuất hiện khi chiều dài dây rốn chiếm hơn 4/5 chiều dài thai nhi, có thể làm thay đổi tân số tim thai. Áp lực tử cung tăng trong lúc chuyển dạ gây tăng áp lực liên tục trên dây rốn có thể có hại cho thai nhi [1],[3]. Tuy nhiên, một số tác giả không tìm thấy mối liên quan giữa DRQC với bất Iợi cho thai kỳ [4] [8]. Thực tế DRQC luôn là nỗi lo của đa số các thai phụ nhất là trong giai đoạn chuyển dạ và thường yêu câu được sinh mổ thay vì sinh ngã âm đạo. Điều này luôn tạo áp lực cho các bác sĩ sản khoa và nữ hô sinh.

Khảo sát nhanh trong một tháng, tỉ lệ DRQC của các thai phụ đến sinh tại bệnh viện Sản Nhi An Giang là 13\%, trong đó có 4,7\% DRQC nhiều hơn một vòng. Đa số các trường hợp $\mathrm{DRQC}$ từ hai vòng trở lên được chẩn đoán qua siêu âm thường có chỉ định sinh mổ trừ các trường hợp không được biết trước. Trường hợp DRQC một vòng nếu không kèm theo một yếu tố bất thường nào khác sẽ được theo dõi sinh ngã âm 
đạo. Tuy nhiên trong quá trình theo dõi chuyển dạ cho các thai phụ này, các bác sĩ và nữ hộ sinh luôn bị một áp lực rất lớn từ phía thai phụ và người nhà. Với mong muốn có môt chứng cứ khoa học tại cơ sở, chúng tôi tiến hành nghiên cứu này với mục đích xác định mối liên quan giữa DRQC một vòng với kết cục của thai nhi trong chuyển da.

\section{II. ĐỐI TƯợNG VÀ PHƯƠNG PHÁP NGHIÊN CỨU \\ 2.1 Đối tượng nghiên cứu:}

- Tiêu chuấn chọn bênh: các thai phụ chuyển dạ sinh có hoắc không có DRQC một vòng, tuổi thai 38-40 tuần, ngôi đầu và không có chỉ định phẫu thuật lấy thai ở thời điểm nhập viện.

- Tiêu chuấn loại trừ: Thai quá ngày, non tháng; bất thường sản khoa: đa thai, đa ối, thiểu ối, tử cung dị dạng, tiền sản giật, ngôi bất thường (ngôi mông, ngôi ngang hoặc ngôi mặt); có chỉ định phẩu thuật lấy thai ở thời điểm nhập viện như nhau bong non, tim thai suy, nhau tiền đạo ra huyết nhiêu, dọa võ̃ tử cung, đau vết mổ cũ, hoặc tiên lượng có nguy cơ phấu thuật lây thai như con quí, thai to, khung chậu hep, ối võ non, ối võ sớm> 24 giờ, nhiễm trùng ối, vết mổ cũ. Ngoài ra, loại trừ thai nhi có DRQC nhiều hơn một vòng hoặc có tiền sử bệnh lý nội khoa đi kèm.

\subsection{Phương pháp nghiên cứu}

-Thiết kế nghiên cứu: Bệnh chứng 1:2; cứ một trường hợp sinh thường có $\mathrm{DRQC}$ được bắt cặp với 2 trường hợp sinh thường không có $\mathrm{DRQC}$

- Địa điểm nghiên cứu: Phòng sanh, Bệnh viện Sản Nhi An Giang

-Thời gian: từ 01/03/2019 đến 30/12/2019

- Cõ̃ mẫu: Cõ̃ mẫu nghiên cứu được tính theo công thức:

$$
\mathrm{n}=\frac{\left(\mathrm{Z}_{1 / 2} \alpha \sqrt{2 \mathrm{pq}}+\mathrm{Z} 2 \beta \sqrt{\left(\mathrm{p}_{1} \mathrm{q}_{1}+\mathrm{p}_{2} \mathrm{q}_{2}\right)^{2}}\right.}{\left(\mathrm{p}_{1}-\mathrm{p}_{2}\right)^{2}}
$$

Chọn $\mathrm{OR}=3 ; \mathrm{a}=0,05 ; \beta=0,2$ (lực mẫu 0,8 ); với $\mathrm{p}_{1}=0,22$ (Theo Hayes [2] tỉ lệ DRQC một vòng là $22 \%$ ), cõ mẫu tính được là $n_{1}=90$ đối tượng cho nhóm bệnh và $\mathrm{n}_{2}=180$ cho nhóm chứng.

Cách tiến hành: Chọn ngẫu nhiên các thai phụ nhập viện có dấu hiệu chuyển dạ từ 07 giờ sáng đển $17 \mathrm{~h}$ chiều các ngày từ thứ 2 đến thứ 6 trong tuần. Mỗi sản phụ có siêu âm trước sinh với $\mathrm{DRQC}$ được theo dõi và xác định $\mathrm{DRQC}$ một vòng sau sinh. Sẽ loại bỏ nếu không có $D R Q C$ hoặc có $\mathrm{DRQC}$ từ 2 vòng trở lên. Cứ mỗi sản phụ có DRQC một vòng sẽ chọn tiếp 2 sản phụ không có DRQC làm nhóm chứng.
Thu thập dữ liệu: Một biểu mẫu soạn sẵn thu thập các biến nghiên cứu gồm: tuổi mẹ, nghề nghiệp, số lần sinh, tuổi thai, các yếu tố nguy cơ trong chuyển da gồm nước ối nhuộm phân su, sử dụng oxytocin tăng co, nhịp tim thai bất thường. Gihi nhận các biến liên quan kết cục thai nhi gồm phương pháp sinh, cân nặng trẻ, điểm số Apgar của trẻ ở phút đâu tiên sau sinh.

Định nghĩa các biến nghiên cứu:

- Dây rốn quấn cổ một vòng: dây rốn quấn quanh cổ thai nhi 360 độ.

- Nước ối nhuộm phân su: nước ối có màu xanh do thai nhi tống xuất phân su hòa lẫn trong nước ối.

- Sử dụng oxytocin tăng co: Thai phụ được truyền tĩnh mạch Glucose $5 \% 500 \mathrm{ml}$ pha với 1 ống Oxytocin 5 đơn vị, truyền 5-20 giọt/phút trong giai đoạn chuyển dạ để tăng cớn co tử cung thúc đẩy quá trình chuyển dạ.

- Biểu đồ tim thai (cardiotocography) bất thường: biểu đồ tim thai xuất hiện một trong các trường hợp sau: trị số tim thai căn bản nhanh trầm trọng ( $>180$ lần/phút) hoặc chậm trầm trọng (<100 lần/phút), đường biếu diễn tim thai phẳng (dao động nội tại <5) , xuất hiện nhịp giảm muộn (Dip II) hoặc nhịp giảm bất định (Dip III) ít nhất 2 lần trong thời gian 30 phút, nhịp giảm kéo dài $\geq 15$ giây.

- Điểm số Apgar 1 phút : tình trạng sức khỏe của bé ở phút đầu tiên ngay sau sinh dựa trên 5 yếu tố là màu da, nhịp tim, phản xạ kích thích, cử động và hô hấp với thang điểm từ 0 đến 2 cho mối yếu tố. Các điểm này sau đó cộng lại được tính từ 0 đến 10 điểm. Điểm số Apgar phút đầu tiên sau sinh $<7$ được đánh giá là ngạt sau sinh cần phải hồi sức cho trẻ.

- Nghề nghiệp chia thành 2 nhóm: lao động nhẹ (nội trợ, công chức, giáo viên, uốn tóc, làm móng); lao động nặng (buôn bán, làm ruộng, làm mướn, công nhân).

Xử lý số liệu: Dùng phép kiểm $T$ Student cho các biến sổ liên tục có phân phối chuẩn. được xử lý bằng phép kiểm $T$ Student. Dùng phép kiểm Chi-Square hoặc Fisher's exact cho các biến phân loại. Xử dụng phần mềm SPSS 22.0 trong Windows. Các test có sự khác biệt ý nghĩa thống kê khi $P<0,05$.

\section{KẾT QUẢ NGHIÊN CỨU}

Phân tích kết quả ghi nhận được từ 270 thai phụ chuyển dạ sinh gồm 90 trường hợp có $D R Q C$ một vòng và 180 trường hợp không có $\mathrm{DRQC}$, chúng tôi nhận thấy: 
Bảng 1: Đăc điểm dân số nghiên cứu

\begin{tabular}{|c|c|c|c|}
\hline Đặc điểm & $\begin{array}{l}\text { DRQC (+) } \\
(n=90) \%\end{array}$ & $\begin{array}{l}\text { DRQC (-) } \\
(\mathrm{n}=180) \%\end{array}$ & Trị số P \\
\hline $\begin{array}{cc}\text { Tuổi mẹ: } & \leq 18 \\
& 19-34 \\
& \geq 35\end{array}$ & $\begin{array}{c}3(3,3) \\
80(88,9) \\
7(7,8)\end{array}$ & $\begin{array}{c}14(7,8) \\
160(99,9) \\
6(3,3)\end{array}$ & 0,114 \\
\hline $\begin{array}{r}\text { Nghề nghiệp: Lao động nhẹ } \\
\text { Lao động nặng }\end{array}$ & $\begin{array}{l}62(68,9) \\
28(31,1)\end{array}$ & $\begin{array}{l}127(70,6) \\
53(29,4)\end{array}$ & 0,780 \\
\hline $\begin{array}{l}\text { Số lần sinh: Con so } \\
\text { Con rạ }\end{array}$ & $\begin{array}{l}43(47,8) \\
47(52,2)\end{array}$ & $\begin{array}{l}110(61,1) \\
70(38,9)\end{array}$ & 0,037 \\
\hline $\begin{array}{c}\text { Giới tính: Trẻ nam } \\
\text { Trẻ nữ }\end{array}$ & $\begin{array}{l}49(54,4 \\
41(45,6)\end{array}$ & $\begin{array}{l}82(45,6) \\
98(54,4)\end{array}$ & 0,168 \\
\hline $\begin{array}{r}\text { Tuối thai (tuân): } \leq 37 \\
>37\end{array}$ & $\begin{array}{c}2(2,8) \\
70(97,2) \\
\end{array}$ & $\begin{array}{c}13(8,9) \\
133(91,1)\end{array}$ & 0,093 \\
\hline 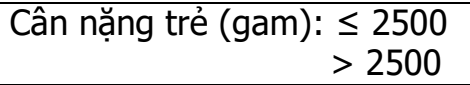 & $\begin{array}{c}4(4,4) \\
86(95,6)\end{array}$ & $\begin{array}{c}12(6,7) \\
168(93,3)\end{array}$ & 0,466 \\
\hline
\end{tabular}

Nhận xét: Không có sự khác biệt về tuối mẹ, nghề nghiệp, giới tính, tuối thai và cân nặng trẻ. Riêng con rạ có tỉ lệ DRQC cao hơn con so $(P=0,037)$

Bảng 2: Các yều tố liên quan đến kêt cục thai kỷ

\begin{tabular}{|c|c|c|c|c|}
\hline Các yếu tố & $\begin{array}{c}\text { DRQC (+) } \\
(\mathbf{n = 9 0 )}\end{array}$ & $\begin{array}{c}\text { DRQC (-) } \\
(\mathbf{n = 1 8 0 )}\end{array}$ & OR (KTC 95\%) & $\begin{array}{c}\text { Trị số } \\
\mathbf{P}\end{array}$ \\
\hline Nước ối nhuộm phân su & $9(10)$ & $10(5,6)$ & $1,9(0,7-4,8)$ & 0,184 \\
\hline Dùng oxytocin tăng co & $10(11,1)$ & $14(7,8)$ & $1,4(0,6-3,4)$ & 0,366 \\
\hline Biếu đồ tim thai bất thường & $4(4,4)$ & $4(2,2)$ & $2,0(0,5-8,3)$ & 0,319 \\
\hline Sinh mố & $17(18,9)$ & $24(13,3)$ & $1,5(0,7-2,9)$ & 0,232 \\
\hline Điểm số Apgar 1 phút < 7 & $2(2,2)$ & $5(2,8)$ & $0,8(0,2-4)$ & 0,479 \\
\hline
\end{tabular}

OR: Odds ratio; KTC 95\%: khoảng tin cậy 95\%; DRQC: Dây rốn quấn cố.

\section{BÀN LUẬN}

Phân tích một số đặc điểm của dân số nghiên cứu có thể ảnh hưởng đến quá trình chuyển dạ như tuổi mẹ, nghề nghiệp liên quan đến lao động nặng, tuổi thai và cẩn nặng trẻ, chúng tôi không thây có sự khác biệt mang ý nghĩa thống kê giữa hai nhóm. Tuy nhiên bà me sinh con rạ có tỉ lệ bị DRQC cao hơn (52,2\% so với 38,9\%; $\mathrm{P}=0,031)$, điều này phù hợp với nghiên cứu của Bernard và $\mathrm{CS}$ [5] sinh nhiêu lần có nguy cơ $\mathrm{DRQC}$ nhiều hơn so với bà mẹ sinh lần đầu.

So sánh quá trình chuyển dạ của hai nhóm có và không có $\mathrm{DRQC}$ chúng tôi không tìm thấy mối liên quan mang ý nghĩa thống kê giữa DRQC một vòng với các yếu tố nguy cơ trong chuyển dạ như nước ối nhuộm phân su, biểu đồ tim thai bất thường, sử dụng oxytocin để tăng co, cũng như kết cục sinh mổ và điểm số Apgar 1 phút $<7(P>0,05)$.

Theo tác giả Trần Quang Hiên, khảo sát trên 358 sản phụ được theo dõi sinh tại bệnh viện Phụ Sản Hùng Vương với 89 trường hợp em bé sinh ra có $D R Q C$ cho thấy ở nhóm có $D R Q C$ tỷ lệ nhịp tim giảm xuất hiện nhiều hơn $(P<0,001)$, tỷ lệ ối nhuộm phân su cao hơn $(P=0,014)$, và tỳ lệ mổ sinh cao hơn $(A O R=2)$, tuy nhiên không có sự khác biệt mang ý nghĩa thống kê về sử dụng oxytocin để tăng co trong chuyển dạ và điểm số Apgar 1 phút và 5 phút [6].

Nghiên cứu của Mastrobattista cho thấy DRQC không làm tăng nguy cơ ối nhuộm phân su, bất thường nhịp tim thai, tỉ lệ sinh mổ nhưng điểm số Apgar 1 phút $<7$ tăng đáng kể $(P=0,01)$ [1]. Ngược lại Peregrine và cộng sự (CS) ghi nhận có sự gia tăng điểm số Apgar 1 phút $<7$ nhưng khổng có ý nghĩa thống kê [7]. Một nghiên cứu hồi cứu dựa vào dân số với cỡ mẫu lớn gổm 166.318 sản phụ, Sheiner và CS [8] nhận thấy tỉ lệ có $\mathrm{DRQC}$ là $14,7 \%$ và không thấy có sự khác biệt về bất thường tim thai, can thiệp sinh cũng như tỉ lệ sinh mổ giữa 2 nhóm. Tỉ lệ điểm số $A p g a r<7$ vào thời điểm 1 phút cao hơn ở nhóm có DRQC (4.8\% so với $4.4 \%$; $P=0.008)$, tuy nhiên vào thời điểm 5 phút thì điểm số Apgar nhóm có $\mathrm{DRQC}$ thấp hơn $(0.5 \%$ so với $0.7 \% ; P=0.004)$. Ngoài ra, tỉ lệ chết chu sinh lại thấp hơn ở nhóm có $\mathrm{DRQC}(11 / 1.000$ so với $16 / 1.000 ; P=0,001)$.

Trong quá trình chuyển dạ, các cơn co tử cung sẽ đẩy thai nhi di chuyển dần xuống cổ tử cung cùng với nhau thai và dây rốn. Do đó $\mathrm{DRQC}$ không gây cản trở cho sự di chuyển của bé và vì 
thế không ảnh hưởng đến tiến trình cuộc chuyển dạ. Khi dây rốn ngắn, $\mathrm{DRQC}$ có thể khiển thai nhi khó lọt, ảnh hưởng tới độ mở cổ tử cung do đầu thai nhi cúi không tốt. Tuy nhiên $\mathrm{DRQC}$ kèm dây rốn ngắn là rất ít. Nhiều nghiên cứu cho thấy chỉ khi dây rốn quấn cổ chặt hoặc quấn nhiều vòng mới có thể khiến thai nhi bị thiếu oxy gây suy thai trong chuyển dạ với hai biểu hiện đặc trưng trên lâm sàng là nước ối nhuộm phân su và nhịp tim thai bất thường.

Tóm lai, với DRQC một vòng rất ít khi gây ra vấn đề bất lợi cho cả me và thai nhi. Thai nhi bị DRQC một vòng có thế được sinh dễ dàng qua ngã âm đạo và an toàn. Giới hạn ở nghiên cứu này là chúng tôi chưa ghi nhận được số trường hợ DRQC một vòng chăt để so sánh với nhóm dây rốn quấn cổ một vòng lỏng cũng như chưa đánh giá được một yếu tố nguy cơ khá quan trọng trong chuyển dạ đó là chuyển dạ đình trệ do ngôi cúi kém. Ngoài ra mẫu nghiên cứu còn nhỏ và chỉ thực hiện ở một trung tâm nên chưa thể suy rộng cho mẫu dân số. Cần thiết có những nghiên cứu tiền cứu, mẫu lớn và đa trung tâm đề khẳng định kết quả này.

\section{KẾT LUẬN}

Chưa tìm thấy mối liên quan giữa dây rốn quấn cổ một vòng với các yếu tố nguy cơ trong chuyển dạ như ổi nhuộm phân su, biểu đồ tim thai bất thường, sử dụng oxytocin để tăng và cũng cũng chưa tìm thấy mối liên quan giữa dây rốn quấn cổ một vòng với kết thúc thai kỳ bất lợi vì vậy can thiệp sinh là không cần thiết ở thai nhi có dây rốn quấn cổ.

\section{TÀI LIẸU THAM KHẢO}

1 Shrestha NS, Singh N. (2007) Nuchal cord and perinatal outcome. Kathmandu Univ Med J (KUMJ). Jul-Sep;5(3):360-3

2. Hayes DJL, Warland J, Parast MM, et al. (2020) Umbilical cord characteristics and their association with adverse pregnancy outcomes: A systematic review and meta-analysis. PLoS One. Sep 24;15(9):e0239630.

3. Sherer DM, Sokolovski M, Dalloul M, KhouryCollado F, Abulafia 0. (2005) Is fetal cerebral vascular resistance affected by the presence of nuchal cord(s) in the third trimester of pregnancy? Ultrasound Obstet Gynecol. May;25(5):454-8.

4. Kong CW, Chan LW, To WW. (2015) Neonatal outcome and mode of delivery in the presence of nuchal cord loops: implications on patient counselling and the mode of delivery. Arch Gynecol Obstet. Aug;292(2):283-9.

5. Bernad ES, Craina M, Tudor A, Bernad SI. (2012) Perinatal outcome associated with nuchal umbilical cord. Clin Exp Obstet Gynecol.;39(4):494-7.

6. Trân Quang Hiền và Nguyêen Ngọc Thoa (2008) "Tỳ lệ dây rốn quấn cổ thai nhi trong chuyển dạ và các yếu tố liên quan". http://hosrem.org.vn/detailNews/thongtin/186

7. Peregrine E, P O'Brian, Jauniaux E.(2005) neck cord Ultrasound detected before induction of labor and cesarean risk. Obstet Gynecol Ultrasound; 25: 160-4.

8. Sheiner E, Abramowicz JS, Levy A, Silberstein T, Mazor M, Hershkovitz R. (2006) Nuchal cord is not associated with adverse perinatal outcome. Arch Gynecol Obstet. May; 274(2):81-3.

\section{TỶ LÊ VÀ MộT SỐ YẾU TỐ LIÊN QUAN ĐẾN HUYẾT THANH DƯƠNG TÍNH VỚI TOXOPLASMA GONDII Ở PHU NỮ TUỔI SINH ĐẺ HUYỆN KRÔNG BÔNG TỈNH ĐẮK LẮK NĂM 2020}

\section{Trần Vũ Hoà ${ }^{1}$, Thân Trọng Quang ${ }^{2}$} Lê Minh Hoài An ${ }^{1}$, Nguyễn Trần Uyên Phương ${ }^{1}$

\section{TÓM TẮT}

Mục tiêu: Bệnh Toxoplasmosis là một vấn đề sức khỏe cộng đồng trên toàn thế giới. Bệnh do ký sinh trùng Toxoplasma gondii (T. gondii) gây ra, là một lọại ký sinh trùng nội bào bắt buộc, có khả năng lây nhiếm nhiều động vật máu nóng bao gồm cả con người, dẫn

\footnotetext{
${ }^{1}$ Bệnh viện Từ Dũ

Đại học Tây Nguyên

Chịu trách nhiệm chính: Nguyễn Trân Uyên Phương

Email: ntuphuong.iu@gmail.com

Ngày nhận bài: 19.11.2020

Ngày phản biện khoa học: 23.12.2020

Ngày duyệt bài: 7.01.2021
}

đến một bệnh phổ biến trên toàn câu, làm ảnh hưởng đến sức khỏe cộng đồng. Xu thế hiện nay đẩy mạnh việc chăm lo cho sức khỏe trong cộng đồng, bệnh do Toxoplasma đang được nhiều nhà̀ nghiên cứu trên toàn thế giới quan tâm từ nhiều khía cạnh khác nhau. Việc nâng cao nhận thức về bệnh $T$. gơndii là rất cần thiết cho phòng ngừa tình trạng lây nhiễm trong cộng đồng, đặc biệt là những phụ nữ trong độ tuổi sinh đẻ, có thể han chế những yếu tố nguy cơ có thể ảnh hưởng đển thời kỳ mang thai. Tại Việt Nam, các nghiên cứu về nhiễm T. gondii trong cộng đồng chưa nhiều, đặc biệt khu vực miền Trung và Tây Nguyên cho đến nay rất ít đề tài nghiên cứu nhiễm $T$. gondii. Để xác định tỷ lệ huyết thanh dương tính $T$. gondii cũng như một số yếu tố liên quan góp phần vào sự lưu hành của bệnh và đề xuất biện pháp phòng 